\title{
The Relationshipbetween Self-Efficacy for Exercise and Knee Pain among Older Adults with Knee Pain in Community- Dwelling of Bangkok Metropolis, Thailand
}

\author{
Pattaraporn Piwong ${ }^{1}$, Tiwaporn Junkhaw ${ }^{2}$, Ratana Somrongthong ${ }^{3}$ \\ ${ }^{1}$ Ph.D Student, College of Public Health Sciences, Chulalongkorn University, Bangkok, Thailand, ${ }^{2}$ Lecturer, \\ Phetchabun Provincial Public Health Office, Thailand, ${ }^{3}$ Associate Professor of Public Health,College of Public \\ Health Sciences, Chulalongkorn University, Bangkok, Thailand
}

\begin{abstract}
Objectives: Aimedto describe demographic characteristics, history of knee pain, history of exercise and assess the relationship between self-efficacy for exercise and knee pain among older adults with knee pain in community-dwelling of Bangkok, Thailand

Method: A cross-sectional study enrolled 220 participants with knee pain aged 50-65 yearsresponded to a structured questionnaire, numeric pain rating scale (NPRS), and self-efficacy for exercise questionnaires (SEE). Descriptive statistics and Pearson's correlation coefficient were used to analyze data.

Results: Knee pain was found in females more than males $(64.1 \%, 35.9 \%)$. Participants had moderate pain with a low level of SEE and over $80 \%$ of them exercise less than 3 days per week include never exercise. A significant inverse relationship was found between SEE and NPRS.
\end{abstract}

Keywords: Knee pain, Self-efficacy for exercise, Older adults

\section{Introduction}

Knee pain is a common health problem among older adults ${ }^{(1)}$ and its leads to physical disability and restriction in activities of daily living (ADL). ${ }^{(2)}$ Prevalence of knee pain in older adultsat age over 50 years ranges from $33 \%$ (as knee pain on most days for one month or longer) ${ }^{(3)}$ to $47 \%$ (as knee pain in or

\section{Corresponding Author:}

\section{Dr. Ratana Somrongthong}

Associate Professor, College of Public Health Sciences, Chulalongkorn University, Thailand. Institute Building 2-3, SoiChulalongkorn 62, Phyathai Rd., Pathumwan, Bangkok 10330, Thailand.Email: Ratana3@chula.co.th around the knee in the last year). ${ }^{(4)}$ The most common cause of knee pain related to aging also agedassociated with a decline in physical functions ${ }^{(5)}$, therefore leading to major musculoskeletal problemsinthe older adults. Exercise is one of the most effective non-pharmacological treatments to reduce knee pain because it safe and low-costmethod for treating an older adult with knee pain ${ }^{(6)}$ that has been shown to relieve knee pain, improve the functional performance of the knee,delay further progression and prevent osteoarthritis in the future. $(7,8)$ The simple types of exercise for treating knee pain consist of knee range of motion exercise, aerobic exercise (such as cycling, jogging, and swimming), strengthen exercise (mainly to strengthen surrounding muscles from the knee joint). ${ }^{(7)}$ Despite previous studies has shown 
the benefits of enhanced exercise, many older adults remain physically inactive. ${ }^{(9,10)}$ From prior studies have found that only $41.4 \%$ of Thai older adults have been found to exercise ${ }^{(11)}$. The Thai health policy recommendations that every Thai older adult should perform exercise 30 minutes a day, 3-5 days per week, and being physically active but $60-70 \%$ of Thai older adults did not meet the goal ${ }^{(11)}$ and older adults with knee pain have had restricted activity because of the pain then their activity levels could be much lower than among the general population.Therefore, it is important to understand the situation of knee pain in older adults and their exercise history that would facilitate an intervention program to encourage them to exercise which essential for those who live in suburban communities.

To date, most previous studies focus on the only groupof older with knee osteoarthritis ${ }^{(12)}$ but there is no evidence concerning older adults in community-dwelling at ages starting from 50 years who had onset knee pain but not progression toknee osteoarthritis. Consequently, it is reasonable to concentrate on onset knee pain in this group and investigate their demographic characteristics and knee pain problems that would help to delay or prevention of knee pain progression among this group.

Self-efficacy playsan important role in health behavior, the concept of self-efficacy defined as perceived capability and confidence, specific to a particular domain of a person's behavior, ${ }^{(13)}$ which it has been one of the most constantly described relates to exercise behavior. ${ }^{(14)}$ In older people, self-efficacy is a key factorof their beginning and maintenance to their goal-related exercise behaviors. There is currently limited understanding about self-efficacy among older adults who had onset knee pain, especially in Bangkok Thailand. This information could benefit for public health professionals to evaluate and develop an appropriate health interventions program to reduce knee pain, improve self-efficacy, and prevention of knee osteoarthritis for older adults in the future.

Objectives of the study: 1) To describe knee painand their exercises and 2) to identify the relationship between self-efficacy for exercise and knee pain among older adults with knee pain in community-dwelling of Bangkok metropolis.

\section{Materials and Method}

An observational cross-sectional study was conducted incommunity-dwelling older adults who have had diagnosed knee pain by physicians at the selected public health center of Bangkok and participants had been recruited by using a convenient sampling method. The period of study started from August to September 2020.Total 220 participants were selected from inclusion criteria included: (1) both male and female gender (2) age 50-65 years (3) having knee pain either left, right or both knee during movement, knee pain at least on most days in a week or more within the past 12 months(4) able to understand Thai language (5)Willingness to participate in the study. Older adults presented with diagnosed osteoarthritis knee with radiologically confirmed or previous surgery any knee joint,visual and hearing impairment were excluded.

Measurement tool:This tool was developed by the researchers, based on reviewing related literature and experts' opinions, written in Thai language, The tools were organized into 3 parts.

Part 1: Demographic characteristics. This part included gender, age, BMI, education, marital status, occupation, salary,medical history, knee pain, exercise.

Part2: Numeric pain rating scale (NPRS)is a verbally-administered to measure knee pain in this study (scored from 0 - 10) with $0=$ no pain 
and $10=$ the worst pain imaginable ${ }^{(15)}$. The values of NPRS cut-off pointas scores $\leq 3=$ mild pain, scores $4-6=$ moderate pain, scores $\geq 7=$ severe pain. $^{(16)}$

Part 3:Self-efficacy for exercise scale (SEE), the SEE measured perceived exercise capability of participants in many conditions for instance feeling bored, bad weather. ${ }^{(17)}$ The score range from 0-90, and a cut-off point is divided into 3 levels as following; ${ }^{(18)}$ low level = score 0-44.9,score 45.0-71.9 = moderate level and score 72.0-90.0 = high level respectively.
Data collection procedures:Participants completed a face-to-face interview. The data collection was done in 8 weeks at a selected community in Saimai district of Bangkok. All demographic data and structured questionnaireswere collected by researchers.

Data Analysis:the data were analyzed by SPSS version 22, descriptive and correlational analyses (such as means,standard deviations, and Pearson's correlation coefficient) were used to describe and determine the association between knee pain andselfefficacy for exercise, a P-value below 0.05 was considered statistically significant.

\section{Results}

Table 1:Demographic characteristics, history of knee pain, history of exercise, Self-efficacy for exercise (SEE), $n=220$

\begin{tabular}{|c|c|}
\hline Variable & Frequency (\%) \\
\hline $\begin{array}{c}\text { Demographic characteristics } \\
\text { Gender } \\
\text { Male } \\
\text { Female }\end{array}$ & $\begin{array}{c}79(35.9) \\
141(64.1)\end{array}$ \\
\hline $\begin{array}{c}\text { Age (Years) } \\
\quad 50-55 \\
56-60 \\
61-65 \\
\text { Age, mean (SD) }\end{array}$ & $\begin{array}{c}48(21.8) \\
92(41.8) \\
80(36.4) \\
58.60(3.46)\end{array}$ \\
\hline $\begin{array}{c}\text { *Body mass index }(\mathbf{B M I}), \mathbf{~} \mathbf{k g} / \mathbf{m}^{2} \\
\text { 18.5-22.9 Normal } \\
23-24.9 \text { Overweight } \\
\geq 25 \text { Obese } \\
\text { BMI mean (SD) }\end{array}$ & $\begin{array}{l}73(33.2) \\
84(38.2) \\
63(28.6) \\
23.74(1.76)\end{array}$ \\
\hline $\begin{array}{c}\text { Education } \\
\text { Primary school } \\
\text { Secondary School } \\
\text { High School/Diploma degree } \\
\text { Bachelor degree } \\
\text { Master degree or higher }\end{array}$ & $\begin{aligned} 26 & (11.8) \\
61 & (27.7) \\
81 & (36.8) \\
45 & (20.5) \\
7 & (3.2)\end{aligned}$ \\
\hline
\end{tabular}


Cont... Table 1:Demographic characteristics, history of knee pain, history of exercise, Self-efficacy for exercise (SEE), $n=220$

\begin{tabular}{|c|c|}
\hline $\begin{array}{c}\text { Marital Status } \\
\text { Single } \\
\text { Married } \\
\text { Widowed } \\
\text { Divorced/Separated }\end{array}$ & $\begin{array}{c}27(12.3) \\
154(70.0) \\
23(10.5) \\
16(7.3)\end{array}$ \\
\hline $\begin{array}{c}\text { Occupation } \\
\text { Unemployed } \\
\text { Retried government officer } \\
\text { Government officer/ State enterprise employee } \\
\text { Company employee } \\
\text { Self-employed } \\
\text { Merchant } \\
\text { Employee }\end{array}$ & $\begin{array}{ll}11 & (5.0) \\
25 & (11.4) \\
11 & (5.0) \\
27 & (12.3) \\
35 & (15.9) \\
65 & (29.5) \\
46 & (20.9)\end{array}$ \\
\hline $\begin{array}{c}\text { Income (THB per month) } \\
<5,000 \text { THB }(<155.6 \text { USD) } \\
5,001-10,000 \text { THB }(\sim 155.7-311.2 \text { USD) } \\
10,001-15,000 \text { THB }(\sim 311.3-466.9 \text { USD }) \\
15,001-20,000 \text { THB }(\sim 467.0-622.5 \text { USD }) \\
>20,000 \text { THB }(>622.6 \text { USD })\end{array}$ & $\begin{array}{cc}19 & (8.6) \\
65 & (29.5) \\
88 & (40.0) \\
31 & (14.1) \\
17 & (7.7)\end{array}$ \\
\hline $\begin{array}{c}\text { Have underlying disease } \\
\text { Yes } \\
\text { No }\end{array}$ & $\begin{array}{l}174(79.1) \\
46(20.9)\end{array}$ \\
\hline $\begin{array}{c}\text { Knee pain } \\
\text { Side of knee pain } \\
\text { Right knee } \\
\text { Left knee } \\
\text { Both knee } \\
\text { The average duration of knee pain } \\
\text { Less than } 7 \text { Days } \\
1-4 \text { weeks } \\
\text { More than } 1 \text { month but less than } 3 \text { month } \\
\text { More than } 3 \text { months } \\
\text { Frequency of knee pain } \\
\text { All the time } \\
\text { Everyday } \\
\text { Every other day } \\
\text { Every week } \\
\text { Every month }\end{array}$ & $\begin{array}{c}112(50.9) \\
85(38.6) \\
23(10.5) \\
5(2.3) \\
42(19.1) \\
70(31.8) \\
103(46.8) \\
4(1.8) \\
39(17.7) \\
57(25.9) \\
104(47.3) \\
16(7.3)\end{array}$ \\
\hline
\end{tabular}


Cont... Table 1:Demographic characteristics, history of knee pain, history of exercise, Self-efficacy for exercise (SEE), $n=220$

\begin{tabular}{|c|c|}
\hline Exercise & \\
Frequency of usual exercise & \\
Never & $28(12.7)$ \\
1 day per week & $107(48.6)$ \\
2 days per week & $61(27.7)$ \\
3 days per week or more & $24(10.9)$ \\
Duration of exercise per time (n= 192) & $92(47.9)$ \\
$<20$ minutes & $59(30.7)$ \\
$20-30$ minutes & $31(16.1)$ \\
$31-60$ minutes & $10(5.2)$ \\
$>60$ minutes & \\
& \\
Mild pain & \\
Moderate pain & $39(17.7)$ \\
Severe pain & $169(76.8)$ \\
NPRS mean (SD) & $12(5.5)$ \\
Self-efficacy for exercise (SEE) & $4.67(1.15)$ \\
Low(score 0-44.9) & $125(56.8)$ \\
Moderate (45.0-71.9) & $95(43.2)$ \\
High (72.0-90.0) & $0(0)$ \\
SEE mean (SD) & $44.41(5.13)$ \\
\hline
\end{tabular}

*WHO, BMI for Asian populations ${ }^{(19)}$

The characteristic of participants showed in Table1. The majority of older adults with knee pain were female $(64.1 \%)$. The mean age of participants was 58.6 years $(\mathrm{SD}=3.46)$. Most of them were overweight $(38.2 \%)$ as BMI range from 23 to 24.9 $\mathrm{kg} / \mathrm{m}^{2}$, were graduated high school or diploma degree $(36.8 \%)$, and up to $70 \%$ were married. In regards to occupation and salary, $29.5 \%$ of participants were merchants with monthly income 10,001-15,000 THB( $~ 311.3-466.9$ USD) (40\%). In addition, the majority $(50.9 \%)$ reported knee pain at the right side withpain more than 3 months $(46.8 \%)$ through every week (47.3\%). Furthermore, they have shown thatmore than two-thirds $(76.8 \%)$ had moderate pain levels with an average of NPRS $4.67 \pm 1.15$.

Overall, they were less likely to exercise regularly, only $10.9 \%$ of participants met the criteria as Thai health policyrecommendations ${ }^{(20)}, 48.6 \%$ were exercise only 1 day per week and $12.7 \%$ were inactive as reported never exercise.Moreover, it appears that people who exercise, theyexercise less than 20 minutes per time up to $47.9 \%$. Regarding SEE, the mean was $44.41(\mathrm{SD}=5.13)$ and more than a half $(56.8 \%)$ also reported having a low level of SEE. 
Table 2: Correlation between Self-efficacy for exercise and Numeric pain rating scale

\begin{tabular}{|lcc|}
\hline Variable & \multicolumn{3}{c|}{ Correlation coefficient with NPRS } \\
& Self-efficacy for exercise (SEE) $\quad$ r $p$-value \\
\hline & SEE & $-0.1760 .009 * *$ \\
\hline
\end{tabular}

$* * P<0.01$

The result of analysis in table 2 showed that there was statistically significant inverse relationship between self-efficacy for exercise and NPRS ( $\mathrm{r}=$ $-0.176, \mathrm{P}<0.01)$.

\section{Discussion}

The present study aimed to understand demographic characteristics, history of knee pain and exercise, and determine associations between selfefficacy for exercise and knee pain in Thai communitydwellingolder adults with knee pain. As variations in the definition of knee pain, knee pain in the older adult group is common worldwide. The previous studies in China with knee pain older ${ }^{(21)}$, the knee was usually reported as "site of pain complaints", associated with many recent studies in European countries. ${ }^{(22,}$ ${ }^{23)}$ Also consistent with previous literature ${ }^{(24)}$, knee pain occurrence generally in community-dwelling older adults and this study revealed that knee pain in women $(64.1 \%)$ had a higher percentage than in men $(35.9 \%)$. Knee pain universally increases with age, about $25 \%$ of people at age more than 55 years reported knee pain in the past year. ${ }^{(23)}$ Similar toour study,almost two-thirds of participants aged more than 55 years reported knee pain.Another factor observed in this study that influence knee pain was BMI. The mean BMI in this study was 23.74 (SD $=1.76$ ) and most of the participants were overweight $(38.2 \%)$. This concurs with previous studies was found older who are overweight significantly more likely to have daily knee pain. (25) Although our findings illustrate that high BMI in an older adult with knee pain, indicating overweight as a possible cause of knee pain, the cross-sectional-study design of this study limits the ability to rule out other explanations. One such explanation might be a high BMI come after knee pain. That is, knee pain in older adults with normal weight may lead to a modern sedentary lifestyle behavior that contributes to weight gain. Moreover, the possible reason according to Thai culture, most of Thai people like to do floor activities such as kneeling on the flooror squatting and side knee bending through their daily works and activities ${ }^{(26)}$. These activities'posturesmight accelerate the wearand-tear on the knee joint and cause of knee pain.

We found that most of the participants in this study had a low level of self-efficacy for exercise is consistent with previous studies. ${ }^{(7,27)}$ Moreover, the low average score of self-efficacy for exerciseindicates that older adults with knee pain will tend toward inactive and did less exercisesas the consequence of worsening knee pain and disability. In addition, our results revealed that overall they had less exercise, this is in line with the study of Holden ${ }^{(28)}$ which older adults with knee pain were not sufficiently active to achieve the benefits of exercise because of their problem withthe knee joint and their health condition. Furthermore, our result showed that self-efficacy for exercise significant inverse relationship with knee pain. This finding correlates with previous studies that self-efficacy for exercise is important to understanding for those with knee pain, as older with high-level selfefficacy for exercise had a low level of knee pain and being active ${ }^{(29)}$, it is indicating that both self $\square$ efficacy for exercise and knee pain among the older 
adults group are key goals to explore that could be targeted to develop primary care interventions which appropriate for community-dwelling older adults.

\section{Limitations}

Our study is limited by a cross-sectional study with small sample size, the findings in this study will be difficult as our eligible study population was derived from Bangkok Thailand. Therefore, these results might not translate to older adults with knee pain in others countries. Although this, the study findings bling to light and could still be valuable in helping to design acceptableinterventions for people with knee pain in primary health care across different countries.

\section{Conclusion}

Base on this research results, Thai older adults with knee pain had moderate pain with low selfefficacy for exercise and inactive. Moreover, selfefficacy for exercise of those people associated with knee pain. Older adults with knee pain may need further interventions to reinforce the importance of exercise, increase self-efficacy and reduce knee pain.

Source of Funding: Supported by the 90th Anniversaryof Chulalongkorn University Scholarship under theRatchadaphisekSomphot fund,research project no. (GCUGR1125621049D)

\section{Conflict of Interest:Non}

Ethical Clearance: The study was approved by The Research EthicsReview Committee for Research Involving Human Research Participant, Health Science Group, Chulalongkorn University, Bangkok, Thailand (COA No.166/2020).

\section{References}

1. Symmons DP. Knee pain in older adults: the latest musculoskeletal "epidemic". Ann Rheum Dis. 2001;60(2):89-90.
2. Fukutani N, Iijima H, Aoyama T, Yamamoto Y, Hiraoka M, Miyanobu K, et al. Knee pain during activities of daily living and its relationship with physical activity in patients with early and severe knee osteoarthritis. Clinical Rheumatology. 2016;35(9):2307-16.

3. Dawson J, Linsell L, Zondervan K, Rose P, Randall T, Carr A, et al. Epidemiology of hip and knee pain and its impact on overall health status in older adults. Rheumatology. 2004;43(4):497504.

4. Jinks C, Jordan K, Ong B, Croft P. A brief screening tool for knee pain in primary care (KNEST). 2. Results from a survey in the general population aged 50 and over. Rheumatology. 2004;43(1):55-61.

5. Nguyen US, Zhang Y, Zhu Y, Niu J, Zhang B, Felson DT. Increasing prevalence of knee pain and symptomatic knee osteoarthritis: survey and cohort data. Ann Intern Med. 2011;155(11):72532.

6. Holden MA, Nicholls EE, Young J, Hay EM, Foster NE. Exercise and physical activity in older adults with knee pain: a mixed methods study. Rheumatology. 2014;54(3):413-23.

7. Quicke JG, Foster NE, Thomas MJ, Holden MA. Is long-term physical activity safe for older adults with knee pain?: a systematic review. Osteoarthritis and Cartilage. 2015;23(9):144556.

8. Peterson NE, Osterloh KD, Graff MN. Exercises for older adults with knee and hip pain. The Journal for Nurse Practitioners. 2019;15(4):2637. e3.

9. Langhammer B, Bergland A, Rydwik E. The Importance of Physical Activity Exercise among Older People. Biomed Res Int. 2018;2018:7856823-.

10. McPhee JS, French DP, Jackson D, Nazroo 
J, Pendleton N, Degens H. Physical activity in older age: perspectives for healthy ageing and frailty. Biogerontology. 2016;17(3):567-80.

11. Kraithaworn P, Sirapo-ngam Y, Piaseu N, Nityasuddhi D, Gretebeck KA. Factors predicting physical activity among older Thais living in low socioeconomic urban communities. Pacific Rim International Journal of Nursing Research. 2011;15(1):39-56.

12. Blagojevic $M$, Jinks $C$, Jeffery A, Jordan K. Risk factors for onset of osteoarthritis of the knee in older adults: a systematic review and meta-analysis. Osteoarthritis and cartilage. 2010;18(1):24-33.

13. Bandura A. Self-efficacy: toward a unifying theory of behavioral change. Psychological review. 1977;84(2):191.

14. McAuley E, Blissmer B. Self-efficacy determinants and consequences of physical activity. Exerc Sport Sci Rev. 2000;28(2):85-8.

15. Hawker G, Mian S, Kendzerska T, French M. Measures of adult pain: visual analog scale for pain (vas pain), numeric rating scale for pain (NRS pain). McGill pain questionnaire (MPQ), short-form McGill pain questionnaire (SF-MPQ), chronic pain grade scale (CpGs), short Form-36 bodily pain scale (SF Arthritis Care Res 2011.63.

16. Boonstra AM, Stewart RE, Köke AJ, Oosterwijk RF, Swaan JL, Schreurs KM, et al. Cut-off points for mild, moderate, and severe pain on the numeric rating scale for pain in patients with chronic musculoskeletal pain: variability and influence of sex and catastrophizing. Frontiers in psychology. 2016;7:1466.

17. Resnick B, Jenkins LS. Testing the reliability and validity of the Self-Efficacy for Exercise scale. Nurs Res. 2000;49(3):154-9.

18. Pedersen MM, Zebis MK, Langberg H, Poulsen OM, Mortensen OS, Jensen JN, et al. Influence of self-efficacy on compliance to workplace exercise. International Journal of Behavioral Medicine. 2013;20(3):365-70.

19. Consultation WE. Appropriate body-mass index for Asian populations and its implications for policy and intervention strategies. Lancet (London, England). 2004;363(9403):157-63.

20. Committee NHP. The 9th Health Development Plan in the 9th National Economic and Social Development Plan (2002-2006). Bangkok (Bangkok): Express Transportation Organization of Thailand. 2001.

21. Woo J, Ho S, Lau J, Leung PC. Musculoskeletal complaints and associated consequences in elderly Chinese aged 70 years and over. Journal of rheumatology. 1994;21(10):1927-31.

22. Badley EM, Tennant A. Changing profile of joint disorders with age: findings from a postal survey of the population of Calderdale, West Yorkshire, United Kingdom. Ann Rheum Dis. 1992;51(3):366-71.

23. Peat G, McCarney R, Croft P. Knee pain and osteoarthritis in older adults: a review of community burden and current use of primary health care. Ann Rheum Dis. 2001;60(2):91.

24. Kim IJ, Kim HA, Seo Y-I, Jung YO, Song YW, Jeong JY, et al. Prevalence of knee pain and its influence on quality of life and physical function in the Korean elderly population: a community based cross-sectional study. Journal of Korean medical science. 2011;26(9):1140.

25. Rogers MW, Wilder FV. The association of BMI and knee pain among persons with radiographic knee osteoarthritis: A cross-sectional study. BMC Musculoskeletal Disorders. 2008;9(1):163.

26. Sansila P, Eungpinichpong W, Buakate L, Ruangrungsi N. The efficacy of court-type Thai traditional massage on knee pain relief in osteoarthritis patients. Journal of Health 
Research. 2014;28(2):121-6.

27. Rawiworrakul T, Sirapo-ngam Y, Davis AHT, Malathum P, Kulthanan T, Vorapongsathorn T. A community-based exercise program promotes self-efficacy for exercise among Thai women with osteoarthritis of the knee. Thai J Nurs. 2007;132.
28. Holden MA, Nicholls EE, Young J, Hay EM, Foster NE. Exercise and physical activity in older adults with knee pain: a mixed methods study. Rheumatology (Oxford). 2015;54(3):413-23.

29. Quicke JG, Foster NE, Ogollah RO, Croft PR, Holden MA. Relationship between attitudes and beliefs and physical activity in older adults with knee pain: secondary analysis of a randomized controlled trial. Arthritis care \& research. 2017;69(8):1192-200. 